\title{
Comparative Evaluation of Different Soft Tissue Coverage Techniques at Immediate Implant Sites: A Cohort Study
}

Soumya Anugraha Rajan ${ }^{1}$, Biniraj Kannanganatt Ramabhadran ${ }^{2}$, Rishi Emmatty ${ }^{3}$, Tony P Paul ${ }^{4}$, Priya Jose ${ }^{5}$, Divyasree Kochilat Ameyaroy $^{6}$, Preena Thalakottukara Variath ${ }^{7}$, Mary Joseph ${ }^{8}$

\begin{abstract}
Aim and objective:To compare the mucosal thickness, width of attached gingiva, and extent of coverage achieved with the usage of connective tissue graft, platelet-rich fibrin (PRF) membrane and buccally advanced flap along with bone grafts in the closure of immediate implant site.

Materials and methods: Twenty-one sites requiring immediate implants were randomly divided into three groups of seven samples each. The techniques comprised bone grafting in jumping space along with either buccally advanced flap (group A), PRF membrane (group B), or connective tissue graft (group C) to cover the socket. In each group, the extent of socket coverage, mucosal phenotype, and width of attached mucosa achieved were assessed after 3 months and intercompared with initial measurements to identify the best technique in achieving primary tissue closure of immediate implant sites.

Results: Comparative assessment of gain in attached mucosal width had a remarkable difference in all the groups but exhibited no statistical significance among the groups compared. Also, comparative assessment of mucosal thickness and the extent of socket coverage equally indicated a clinical significance among all groups, but failed to achieve any statistical significance.

Conclusion: All the three techniques were found to be equally effective in achieving additional width of attached mucosa around implants, coverage of mucosa at osteotomy sites, and a thicker mucosal phenotype at implant sites. In comparison with one another, no single technique was found to be advantageous over the other.

Clinical significance: The commonly used three techniques for socket coverage following the immediate implant placement has been proven to be equally effective. Thus, the selection of the technique to meet the objective of complete closure of an extraction socket along with implant platform is left open to operator skill and operation site, which should consider least traumatic and most feasible technique.

Keywords: Bone grafting, Buccally advanced flap, Connective tissue graft, Mucosal phenotype, Platelet-rich fibrin.

The Journal of Contemporary Dental Practice (2021): 10.5005/jp-journals-10024-3208
\end{abstract}

\section{INTRODUCTION}

International Team for Implantology (ITI) defined four treatment options for post-extraction implant placement. As per the implant placement protocol, immediate implant can be placed soon after extraction or on the same day. The ideal conditions for immediate implant sites include intact facial bone wall, thick gingival phenotype, and absence of infection. If these ideal conditions are not met, ITI recommends early implant placement extended to $4-8$ weeks of soft tissue healing. If primary stability is doubtful even after 4-8 weeks, the implant placement should be again extended to 12-16 weeks allowing partial bone healing. When partial bone healing is also not appropriate, the implant placement should be extended to 6 more months allowing complete bone healing, which is considered as delayed implant placement. ${ }^{1}$

Immediate implants are placed into the socket readily after the extraction of tooth, which avoids a second surgery for implant placement. Such implants utilize the time period for healing of extraction sockets and reduce the implant loading time. Immediate implants were found to prevent bone resorption following extraction and also aided in maintaining ridge dimension and height. $^{2}$ These implants often preserve soft tissue profiles and preserve the bone at the site of implantation. ${ }^{3}$ In ideal conditions, if primary stability is achieved, immediate loading can also be done so that patient will be more comfortable with an esthetic and functional prosthetic rehabilitation.

The presence of a thick mucosal phenotype in peri-implant region shows an increase in the width of keratinized tissue, which
${ }^{1-8}$ Department of Clinical Periodontology and Oral Implantology, Royal Dental College, Palakkad, Kerala, India

Corresponding Author: Soumya Anugraha Rajan, Department of Clinical Periodontology and Oral Implantology, Royal Dental College, Palakkad, Kerala, India, Phone: +91 9746610048, +91 9447308747, e-mail: soumyaar267@gmail.com

How to cite this article: Rajan SA, Ramabhadran BK, Emmatty R, et al. Comparative Evaluation of Different Soft Tissue Coverage Techniques at Immediate Implant Sites: A Cohort Study. J Contemp Dent Pract 2021;22(11):1268-1274.

Source of support: Nil

Conflict of interest: None

decreases plaque accumulation around the dental implants, thus preventing the progression of peri-mucositis and peri-implantitis. So, peri-implant soft tissue thickness influences osseointegration and thus the stability of bone-level implants. ${ }^{4}$ Thin gingival phenotype is referred to thickness of gingiva $<1.5 \mathrm{~mm}$, whereas the term "thick gingival phenotype" is applicable to gingival thickness of $>2.0 \mathrm{~mm} .^{5}$

Mucosal phenotype can be enhanced along with implant placement, by using bone graft along with subepithelial connective tissue graft or platelet-rich fibrin (PRF) membrane or even collagen scaffolds. But these techniques involve certain drawbacks like high morbidity for obtaining connective tissue graft from a second surgical site, and also collagen scaffolds can 
be avascular, which may turn into a source of infection at the implant site later. ${ }^{6-8}$

Lang and Loe suggested a width of at least $2 \mathrm{~mm}$ of keratinized mucosa, of which $1 \mathrm{~mm}$ is to be attached. ${ }^{9}$ In implant dentistry, attached mucosa adheres to the surface of titanium implant with the help of hemi-desmosomes. Therefore, a direct anchorage of connective tissue to the surface of implant is not possible and mechanical quality of this attachment is poor. ${ }^{10}$ Thus, an increase in attached mucosal zone can always contribute to a high level of mechanical stability of peri-implant tissue.

The main challenge for a surgeon during the immediate implant placement is achieving a complete socket closure. Commonly encountered problem is the jumping distance, which refers to the space between implant and socket wall surrounding the platform of implants. ${ }^{8}$

An incomplete socket closure can cause exposure of implant surface or even implant threads, which may affect osseointegration of implant and also act as a source of peri-implantitis in the future. Lack of primary closure will also affect the formation of attached mucosal width (AMW) over implants. It can lead to a thin mucosal phenotype, which in turn affects the implant stability or even increases the chances of peri-implantitis. ${ }^{11}$

Socket healing of immediate implants can be enhanced with different types of techniques, including advanced buccal flap with or without bone grafts, or even with soft tissue grafts or PRF membrane. Each technique has its own advantages and disadvantages. Among these, the technique ideal to attain complete socket coverage, gain in width of attached mucosa, and achieve a thick gingival phenotype is yet to be comprehended.

The objectives of this study were to compare the gain in the zone of attached mucosa, thickness of mucosal phenotypes, and extent of coverage achieved in implant sites following the usage of connective tissue graft, PRF membrane, and buccally advanced flap for covering the immediate implant site.

\section{Materials and Methods}

A 3-month cohort study was designed to compare the effectiveness of three different groups in achieving the beneficial mucosal topography at the immediate implant sites. The duration of the study was from August 2017 to February 2019.

Selection of patients for study followed the principles outlined in the Declaration of Helsinki on clinical research involving human subjects. An informed consent to participate in the study was obtained from each patient.

The sample size for the study was determined using $G$ power software, and the total sample size was calculated to be $21 \mathrm{implant}$ sites distributed as seven per group, based upon the reference key articles. ${ }^{2,7}$

The case distribution was randomly assigned to each group, and the tooth of interest in each case was not restricted to any particular area. Systemically and physically healthy patients of age ranging from 18 to 55 were selected as sample subjects. Patients with fair or good simplified oral hygiene status and gingival index score $\leq 2$ (Loe and Sillness) and ideal immediate implant sites without any active periodontal disease or bony pathology were only included. Patients fit to undergo connective tissue grafting procedure or PRF procurement only were selected as sample subjects. Patients with a past history of implant failure and subjects with smoking habits were excluded from the study. Implants indicated adjacent to periodontally weak teeth were also excluded. Six investigators were involved in the procedural methodology of the study.

The three surgical techniques included usage of bone graft along with (1) buccally advanced flap, (2) PRF membrane, and (3) connective tissue graft grouping it to be groups A, B, and C, respectively. The parameters to assess the quantity and quality of soft tissue coverage achieved were the measurement of attached mucosa, mucosal thickness, and extent of socket coverage following the usage of the above-mentioned three techniques.

Careful extraction of tooth without flap elevation was carried out with the standard protocol prescribed for immediate implant procedure to prevent any damage to the surrounding alveolar bone. ${ }^{12}$ The buccolingual width of extraction socket was measured as area between center of facial and lingual marginal gingiva, using a William's periodontal probe during surgery after tooth extraction for future references.

The width of attached mucosa prior to the implant placement was assessed at this point, by measuring the length of the area between the mucogingival junction (MGJ) on both sides in cases of lower jaws and the MGJ on the buccal side to the free gingival groove on the palatal side in cases of maxilla. A palatal stent was prepared in cases of all maxillary immediate implant sites with the superior border of the stent coinciding with the free gingival groove on the palatal side of the tooth to be extracted (Fig. 1). The measurement was done using a flexible endodontic file to compensate the curvature of the ridge at three points of the socket, and the average value of these three measurements were taken as the final value to be recorded. This measurement included the width of socket as this area would turn into a part of attached mucosa in the future. This measurement was recorded as preoperative value of width of attached mucosa in the study.

The implant was positioned in the osteotomy site prepared in the extraction socket, as per the implant planning. ${ }^{13}$ The amount of jumping space around immediate implants was assessed, and in every cases of more than $2 \mathrm{~mm}$ of horizontal defect dimension, the jumping space was restored with bone graft (bioresorbable demineralized bone matrix-DMBM). ${ }^{14}$

Following this procedure, the exposed socket mouth was managed with one of the three study techniques. In group A,

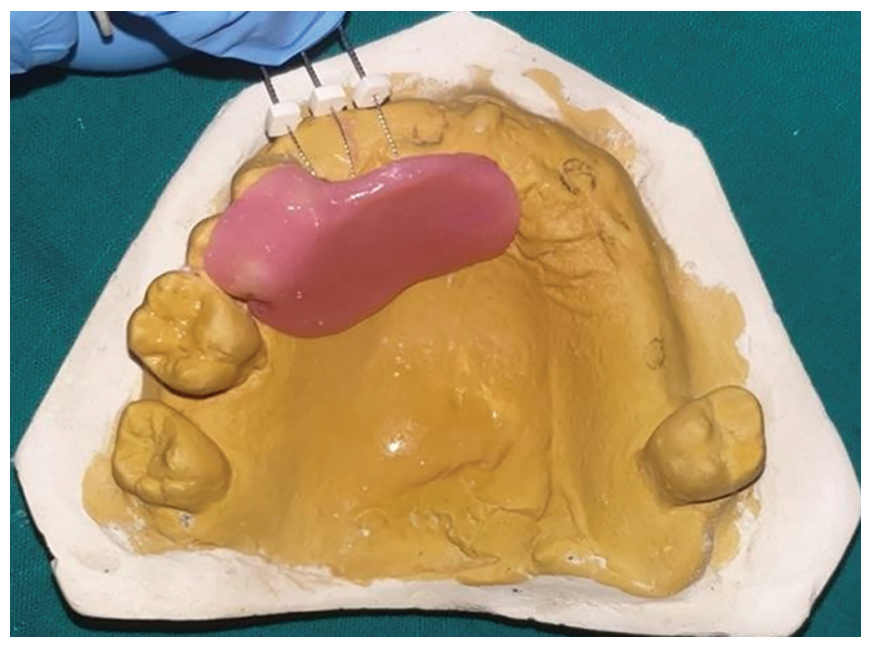

Fig. 1: Custom-made stent for measuring attached mucosal width at the upper-right canine region 
the exposed implant and the socket mouth were managed with buccally advanced flap, wherein a mucoperiosteal flap was raised with two vertical incisions crossing the MGJ and the flap was advanced and sutured on to the fixed palatal/lingual mucosa (Fig. 2),

Among the cases prescribed under group $B$, the exposed socket was covered with a PRF membrane obtained from patient's blood through the classic PRF preparation. ${ }^{15}$ PRF was prepared from 10 cc of blood drawn from patient's arm for each single implant. The blood was transferred to a $10-\mathrm{mL}$ test tube and centrifuged at 3000 rpm for 10-15 minutes. The PRF compartment from the centrifuged mass was separated and gently pressed with the aid of two sterile glass slabs and gauze, and was made into a thin membrane. The PRF membrane was stabilized in position by covering it using the same buccally advanced flap used in group A (Fig. 3).

In cases under group $C$, the exposed socket was managed with a connective tissue graft procured from palate using the classic Edel's trap door technique. ${ }^{16}$ The connective tissue graft was used to cover the socket mouth with its borders tucked into the submucosal area securing the space between bone and the implant. The graft was secured in place by passively suturing the crest of mucosa over it (Fig. 4).

Following the suturing, the thickness of the mucosa overlying the implant was assessed using a sharp graduated probe with a stopper. This thickness was recorded as the preoperative mucosal thickness to be compared with postoperative values at the end of 3 months.

The standard postoperative care protocol for immediate implant procedure was prescribed. Patients were recalled for suture removal after a period of 10 days and were scheduled for a review at the end of 3rd month.

At the end of 3rd month, each of the sample sites was assessed with all the three parameters in order to compare the effect of three different techniques used to achieve the same objectives. The extent of socket coverage was a visual clinical examination, and
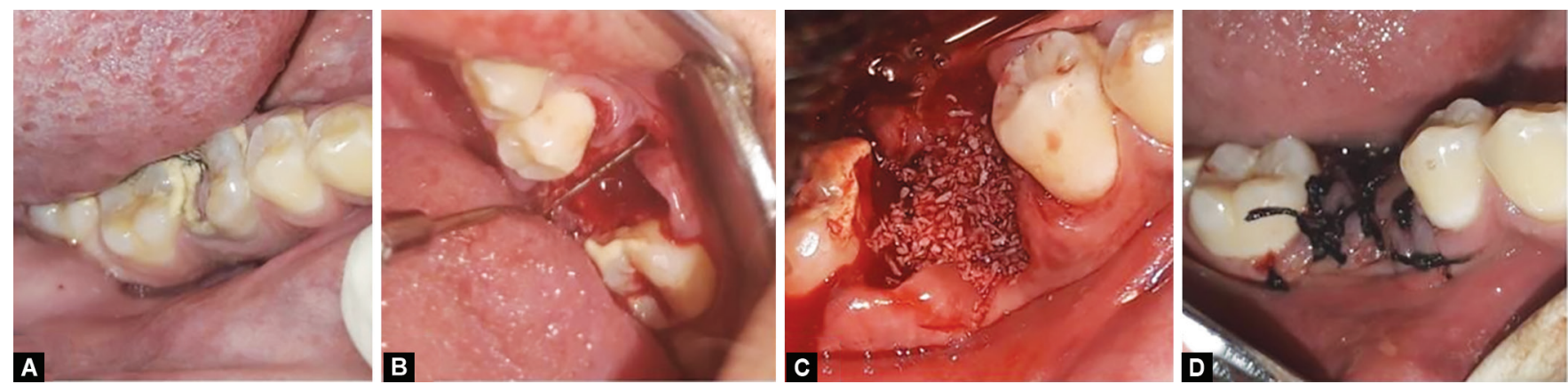

Figs 2A to D: Group A-(A) Preoperative photograph; (B) Measurement of socket width after extraction; (C) Bone graft placed over the implant; (D) Buccally advanced flap utilized and sutures placed to secure the flap
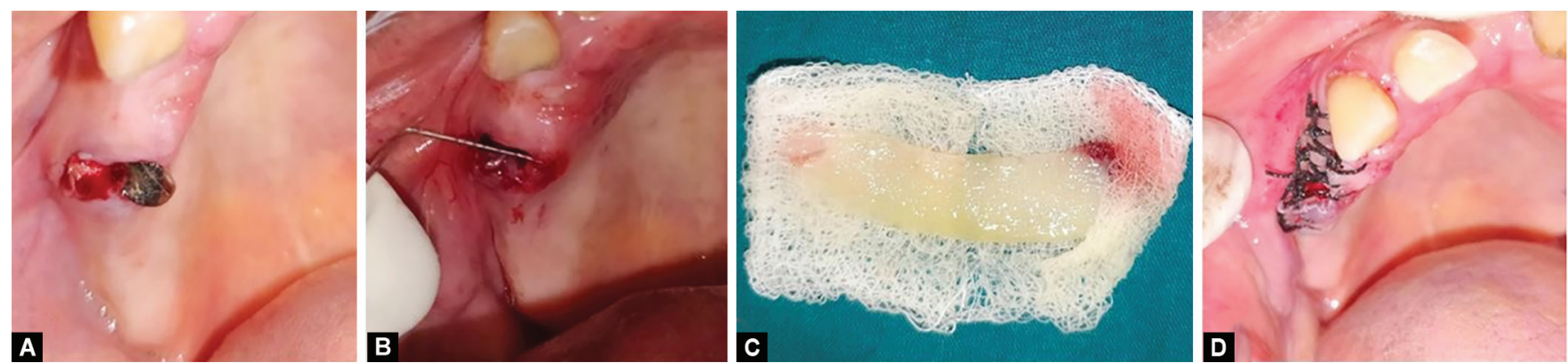

Figs 3A to D: Group B-(A) Preoperative photograph; (B) Measurement of socket width after extraction; (C) PRF membrane prepared; (D) Sutures placed after placing bone graft and PRF membrane
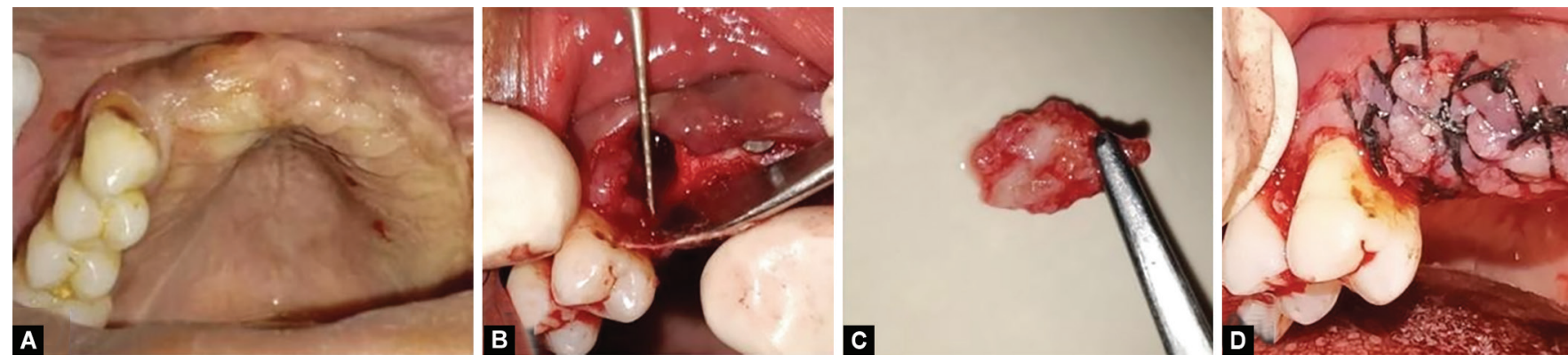

Figs 4A to D: Group C-(A) Preoperative photograph; (B) Measurement of socket width after extraction; (C) Connective tissue graft procured; (D) Sutures placed after placing connective tissue graft 
the objective of this parameter was to understand the capability of each grafting procedure to achieve a complete coverage.

Mucosal thickness over the implant area was measured at the end of 3rd month, using the same graduated straight explorer with a stopper used at the time of surgery. The assessment was done on the mucosa overlying the center of implants. This value was recorded as the postoperative value to be compared with the values recorded at the time of surgery (Fig. 5).

The total attached mucosa at the site of implants was measured in the same way as it was recorded prior to the placement of implants by measuring the mucosal width between the MGJ in cases of lower arch. In maxillary sites, the measurement was assessed using the same stents used for preoperative assessment, since the free gingival groove on the palatal mucosa had disappeared following extractions (Fig. 6).

The mean values obtained in each parameter of assessment were calculated and tabulated separately for intergroup comparison of the results. The observations recorded at baseline and 3rd month of postoperative period were subjected to statistical analysis using simple ANOVA and post hoc Bonferroni test for its intragroup and intergroup comparisons.

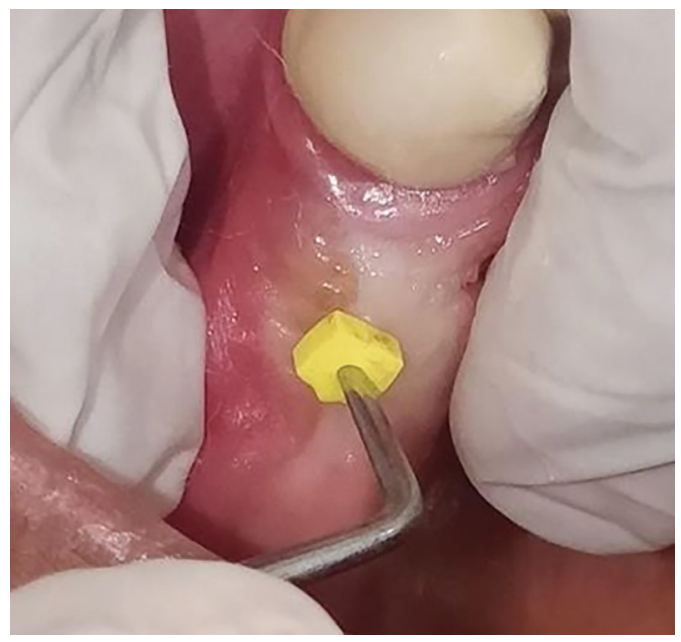

Fig. 5: Measuring mucosal thickness
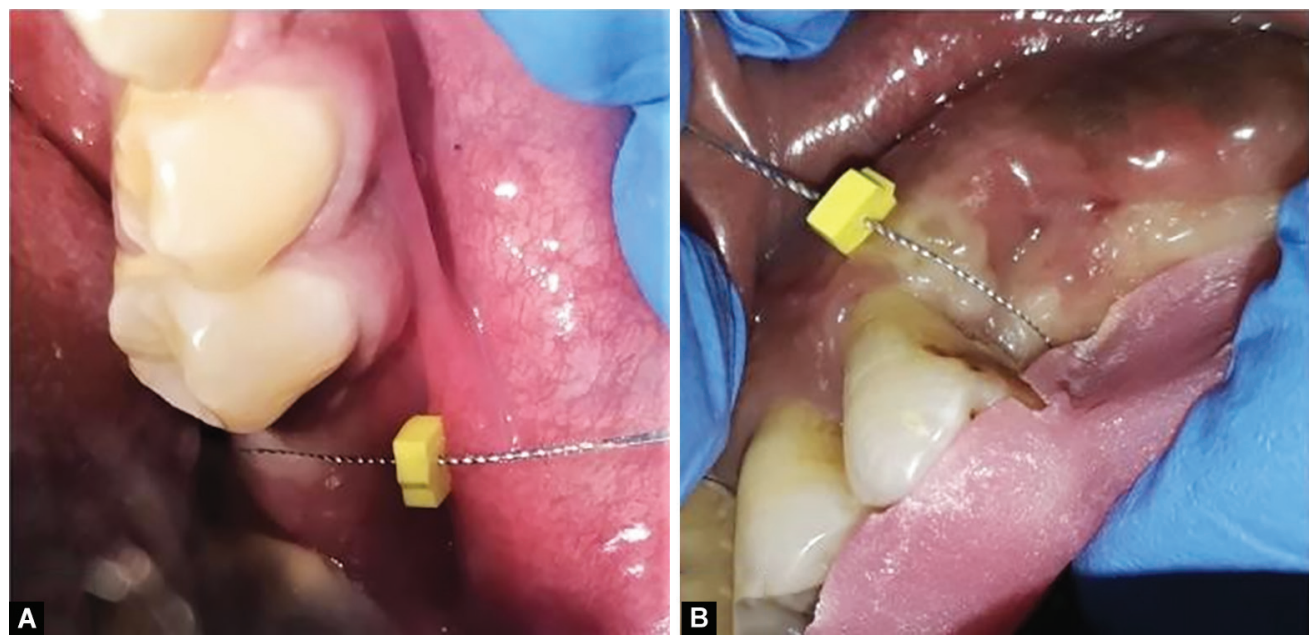

Figs 6 A and B: (A) Measuring attached mucosal width at mandibular sites; (B) Measuring attached mucosal width with stent at maxillary sites
Analytical part was carried out in personal computer through SPSS windows (Statistical Presentation System Software, Version 18 , IBM, USA). In this study, mean and standard deviation of groups were obtained at different time intervals. $p<0.05$ was considered statistically significant.

\section{RESULTS}

The comparative assessment of the extent of socket coverage among groups $A, B$, and $C$ was expressed in millimeters at baseline (Table 1). Samples of all three groups under investigation exhibited complete coverage of immediate implant sockets at the end of 3 months; hence, an intercomparison of its extent of coverage achieved was exempted.

The mean value of AMW at baseline and 3rd month was 7.71 and 7.66 in group A, 8.23 and 7.52 in group B and 13.56 and 13.28 in group C (Fig. 7). None of the groups exhibited a statistically significant difference in comparing the values between pre- and post-intervals $(p=0.438)$.

Though statistically insignificant, the width of attached mucosa at 3rd month postoperative interval showed a slight reduction compared to preoperative level, which indicates a drop in its width. The difference in the values of attached mucosa was calculated to be $-0.045 \mathrm{~mm}$ in group $A,-0.71 \mathrm{~mm}$ in group $B$, and $-0.28 \mathrm{~mm}$ in group C (Table 2).

The mean value of thickness of overlying mucosa at immediate implant sites during the baseline and 3rd month interval was found to be 2.42 and 2.42 in group A, 2.21 and 2.71 in group B, and 2.42 and 2.57 in group $C$ (Fig. 8).

Unlike other groups, the mucosal thickness gained at the end of 3 months was found to be clinically significant in group B, but not statistically significant. Gain in mucosal thickness was $0 \mathrm{~mm}$ in group $A, 0.5 \mathrm{~mm}$ in group $B$, and $0.14 \mathrm{~mm}$ in group $C$ (Table 3).

The commonly used three techniques for socket coverage following the immediate implant placement are proven to be equally effective, but none of them possess no significant advantage over the other.

\section{Discussion}

Similar studies found in the literature on various techniques to cover and augment an open socket after the placement of immediate 
Table 1: Intercomparison of extent of socket coverage among groups $A, B$, and C

\begin{tabular}{lcc}
\hline & \multicolumn{3}{c}{ Intervals of assessment } \\
\cline { 2 - 3 } Group & Baseline (in $\mathrm{mm})$ & 3rd month \\
\hline A & 8.42 & Complete socket coverage achieved \\
B & 6.42 & Complete socket coverage achieved \\
C & 7.42 & Complete socket coverage achieved \\
\hline
\end{tabular}

Data of comparative assessment of extent of socket coverage among groups A, B, and C expressed in millimeters. Every group exhibited complete socket coverage, and hence, no values were available to express the extent of socket coverage at $3 \mathrm{rd}$ month

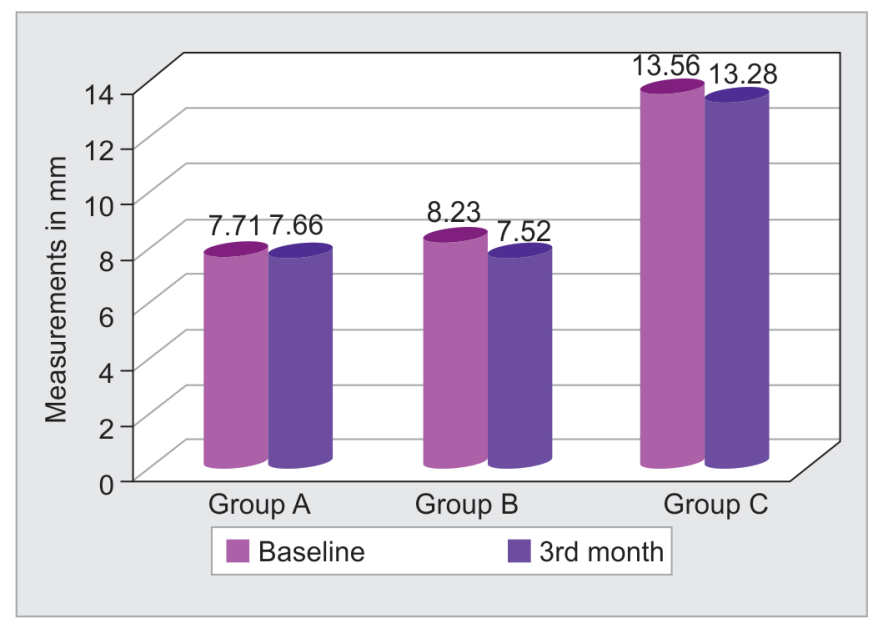

Fig. 7: Attached mucosal width in millimeters among three groups expressed at baseline and 3rd month

Table 2: Intercomparison of attached mucosal width among groups $A, B$, and $C$

\begin{tabular}{|c|c|c|c|c|c|c|}
\hline \multirow[b]{3}{*}{ Group } & \multicolumn{4}{|c|}{ Intervals of assessment } & \multirow{2}{*}{\multicolumn{2}{|c|}{$\begin{array}{l}\text { Gain in attached } \\
\text { mucosal width }\end{array}$}} \\
\hline & \multicolumn{2}{|c|}{ Baseline (in $\mathrm{mm}$ ) } & \multicolumn{2}{|c|}{ 3rd month (in mm) } & & \\
\hline & Mean & $S D$ & Mean & $S D$ & Mean & $S D$ \\
\hline A & 7.71 & 1.55 & 7.66 & 1.51 & -0.045 & 1.06 \\
\hline B & 8.23 & 2.89 & 7.52 & 2.90 & -0.71 & 1.10 \\
\hline C & 13.56 & 1.24 & 13.28 & 1.31 & -0.28 & 0.68 \\
\hline$p$ value & \multicolumn{2}{|c|}{0.001} & \multicolumn{2}{|c|}{0.001} & \multicolumn{2}{|c|}{0.438} \\
\hline
\end{tabular}

Data of comparative assessment of attached mucosal width in millimeters among three groups A, B, C expressed at two intervals, baseline and 3rd month. In group $A$, the gain in attached mucosal width was $-0.045 \mathrm{~mm}$ with a standard deviation of 1.06 . In group $B$, the gain in attached mucosal width was $-0.71 \mathrm{~mm}$ with a standard deviation of 1.10 . In group C, the gain in attached mucosal width was $-0.28 \mathrm{~mm}$ with a standard deviation of 0.68 . Among the groups, there is thorough clinical significance, but statistically failed to exhibit significance in any of the groups

implant included the use of a rotated buccal flap from an adjacent tooth, gingival grafts, palatal advanced flap, ${ }^{6}$ pedicled island flap, ${ }^{7}$ and porcine collagen matrix. ${ }^{17}$ These studies were found to possess several limitations especially in its comparison. None of the studies were done to compare the techniques used to cover surgical site in the immediate implant placement. The studies have ignored to measure the gain in attached gingival zone, which is a major objective of doing such surgeries where attached mucosa is known

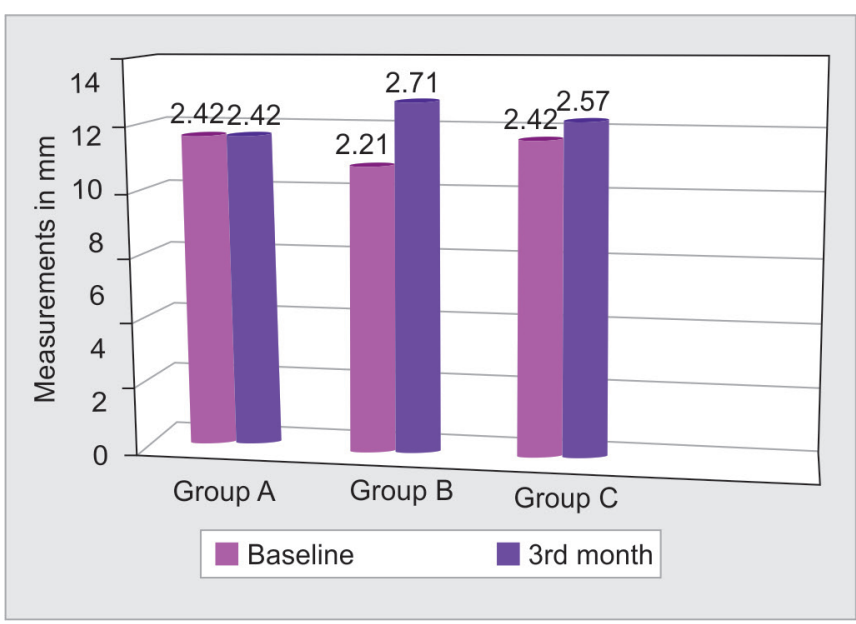

Fig. 8: Mucosal thickness in millimeters among three groups expressed at baseline and 3rd month

Table 3: Intercomparison of mucosal thickness among groups A, B, and C

\begin{tabular}{|c|c|c|c|c|c|c|}
\hline \multirow[b]{3}{*}{ Group } & \multicolumn{4}{|c|}{ Intervals of assessment } & \multirow{2}{*}{\multicolumn{2}{|c|}{$\begin{array}{c}\text { Gain in mucosal } \\
\text { thickness }\end{array}$}} \\
\hline & \multicolumn{2}{|c|}{ Baseline (in $\mathrm{mm}$ ) } & \multicolumn{2}{|c|}{ 3rd month (in $\mathrm{mm}$ ) } & & \\
\hline & Mean & $S D$ & Mean & $S D$ & Mean & $S D$ \\
\hline A & 2.42 & 0.53 & 2.42 & 0.53 & 0 & 0.81 \\
\hline B & 2.21 & 0.56 & 2.71 & 0.75 & 0.5 & 0.50 \\
\hline C & 2.42 & 0.53 & 2.57 & 0.53 & 0.14 & 0.89 \\
\hline$p$ value & \multicolumn{2}{|c|}{0.703} & \multicolumn{2}{|c|}{0.693} & \multicolumn{2}{|c|}{0.462} \\
\hline
\end{tabular}

Data of comparative assessment of mucosal thickness in millimeters among three groups $A, B$, and $C$ expressed at two intervals, baseline and 3 rd month. In group $A$, the gain in mucosal thickness was $0 \mathrm{~mm}$ with a standard deviation of 0.81 . In group $B$, the gain in mucosal thickness was $0.5 \mathrm{~mm}$ with a standard deviation of 0.50 . In group $C$, the gain in mucosal thickness was $0.14 \mathrm{~mm}$ with a standard deviation of 0.89 . Mucosal thickness was found to be clinically significant in group B, but not statistically significant in any of the groups

to play a major role in maintenance of implants. The biotype of the mucosa achieved following socket coverage procedures is of high value but these studies have not focused on this factor, the omission of which is found to be a major limitation.

In the observations of the present study, it was observed that all the three techniques of socket coverage following the immediate implant placement were found to be equally effective in terms of extent of coverage achieved, thickness of overlying mucosa, and the width of attached mucosa gained around the implants.

Implants without keratinized mucosa are believed to possess the same threat on tooth without attached gingiva, making it least defensive against physical trauma and microbial challenges. Such areas tend to accumulate more dental plaque and are prone to develop peri-implant mucositis and eventually peri-implantitis. A similar study on AMW by Adibrad et al., concluded that the absence of adequate keratinized mucosa around implants was associated with higher plaque accumulation, gingival inflammation, bleeding on probing, and mucosal recession. ${ }^{18}$

The connective tissue grafting procedure was incorporated in this socket coverage procedure with an additional intention to augment the soft tissue around the implant area, thereby increasing the zone of attached mucosa. None among the three different 
techniques could achieve a gain in the AMW but all the techniques could resist a reduction in its width limiting it to less than $1 \mathrm{~mm}$. The static measurement in the AMW between the pre-and postoperative intervals becomes more relevant when it is understood that the measurement of the attached mucosa had included the socket mouth at the baseline, and the same measurement was seen to be maintained postoperatively after healing.

Though identical studies were lacking in the literature, the results of the present study were in accordance with few studies based on different objectives. ${ }^{2,19}$ A similar study by Jyothi et al., concluded that immediate implants into a fresh extraction socket, with guided bone regeneration using autologous connective tissue graft, was a promising treatment with successful implant survival rates and an increase in the width of the keratinized mucosa. ${ }^{2}$ A study by Bassetti et al., revealed that apically positioned partial thickness flap in combination with a free gingival graft, subepithelial connective tissue graft, and xenogenic graft material shows an increase in the peri-implant keratinized gingival width. ${ }^{19}$ A study by Frisch et al., concluded the study by proving that the use of partially epithelialized free connective tissue graft results in an increase in the width of keratinized mucosa around implants, which supported the findings of the current study. ${ }^{20}$

The third parameter of assessment of mucosal thickness over the implant was based upon the studies that explain lesser incidence of peri-implant mucositis on tissues having thicker mucosal phenotypes. ${ }^{21,22}$

A study by Bassetti et al., to provide a review of the literature on the role of attached mucosa to maintain peri-implant health indicated that soft tissue conditions should be optimized by various grafting procedures. They also mentioned that when there is insufficient peri-implant soft tissue condition, or uncovered implants, or biologic complications, the treatment appears to be more difficult and less predictable. They concluded that soft tissue grafting can prevent peri-implant tissue breakdown and should be considered when dental implants are placed, which was in accordance with the present study. ${ }^{23}$

All the three techniques maintained the same thickness of mucosa at the time of suturing when reviewed at the end of 3 months. Among the groups, the procedure that utilized PRF along with buccally advanced flap showed a slight increase in mucosal thickness at postoperative level compared with the other techniques, though this finding was not statistically supported.

However, the study observed certain limitations, which included limiting its sample size to seven per group. A larger sample size could have given a more accurate assessment of the techniques used. In addition to this, standardization of the sockets selected for the study could not be achieved due to difficulty in procuring similar sample sites. To a certain extent, the study variables such as age, gender, site, and implant design would have influenced the study.

\section{Conclusion}

Within the limitations of the present study, it can be concluded that none of the techniques used in it showed a significant advantage over the other. Thus, any of the three techniques can be judiciously selected to achieve the aim of complete soft tissue coverage at immediate implant site, as well as to attain an increase in mucosal phenotype or maintain the width of attached mucosa around the implants.

\section{References}

1. Buser D, Sennerby L, De Bruyn H. Modern implant dentistry based on osseointegration: 50 years of progress, current trends and open questions. Periodontol 2000 2017;73(1):7-21. DOI: 10.1111/ prd.12185.

2. Jyothi SG, Triveni MG, Mehta DS, et al. Evaluation of single-tooth replacement by an immediate implant covered with connective tissue graft as a biologic barrier. J Indian Soc Periodontol 2013;17(3):354-360. DOI: 10.4103/0972-124X.115666.

3. Ataullah K, Che LF, Peng LL, et al. Implant placement in extraction sockets: a short review of the literature and presentation of a series of three cases. J Oral Impl 2008;34(2):97-106. DOI: 10.1563/1548-1336(2008)34[97:IPIESA]2.0.CO;2.

4. Esfahrood ZR, Kadkhodazadeh M, Talebi Ardakani MR. Gingival biotype: a review. Gen Dent 2013;61(4):14-17. PMID: 23823337.

5. Seibert JL, Lindhe J, Textbook of clinical periodontology. 2nd ed. In: Lindhe J, editor. Aesthetics and periodontal therapy. Copenhangen, Denmark: Munksgaard; 1989. p. 477-514.

6. Becker W, Goldstein M. Immediate implant placement:treatment planning and surgical steps for successful outcome. Periodontol 2000. 2008;47:79-89. DOI: 10.1111/j.1600-0757.2007.00242.x.

7. Rosenquist B. A comparison of various methods of soft tissue management following the immediate placement of implants into extraction sockets. Int J Oral Maxillofac Implants 1997;12(1):43-51. PMID: 9048453.

8. Rojo R, Prados-Frutos JC, Manchon A. Soft tissue augmentation techniques in implants placed and provisionalized immediately: a systematic review. Biomed Res Int 2016;1-12. DOI: 10.1155/2016/ 7374128.

9. Friedman MT, Barber PM, Mordan NJ, et al. The plaque free zone in health and disease: a scanning electron microscope study. J Periodontol 1992;63(11):890-896. DOI: 10.1902/jop.1992.63.11.890.

10. Jansen JA, De Wijn JR, Wolters Lutgerhorst JM, et al. Ultrastructural study of epithelial cell attachment to implant materials. J Dent Res 1985;64:891-896. DOI: 10.1177/00220345850640060601.

11. Mehta H, Shah S. Management of buccal gap and resorption of buccal plate in immediate implant placement: a clinical case report. J Int Oral Health 2015;7:72-75. PMID: 26225110; PMCID: PMC4516068.

12. Coomes AM, Mealey BL, Huynh BG, et al. Buccal bone formation after flapless extraction: a randomized, controlled clinical trial comparing recombinant human bone morphogenetic protein 2/ absorbable collagen carrier and collagen sponge alone. J Periodontol 2014;85:525-535. DOI: 10.1902/jop.2013.130207.

13. Boora $\mathrm{P}$, Rathee $\mathrm{M}$, Bhoria $\mathrm{M}$. Effect of platelet rich fibrin on peri-implant soft tissue and crestal bone in one-stage implant placement: a randomized controlled trial. J Clin Diagn Res 2015;9(4):18-21. DOI: 10.7860/JCDR/2015/12636.5788.

14. Irinakis T. Rationale for socket preservation after extraction of a single-rooted tooth when planning for future implant placement. J Can Dent Assoc 2006;72(10):917-922. PMID: 17187706.

15. Choukroun J, Diss A, Simonpieri A, et al. Platelet-rich fibrin: a second-generation platelet concentrate. Part IV: Clinical effects on tissue healing. Oral Surg Oral Med Oral Pathol Oral Radiol Endod 2006;101(3):56-60. DOI: 10.1016/j.tripleo.2005.07.011.

16. Edel A. Clinical evaluation of free connective tissue grafts used to increase the width of keratinized gingiva. J Clin Periodontol 1974;1(4):185-196. DOI: 10.1111/j.1600-051x.1974.tb01257.x.

17. Castro Y, Grados S, Grados S. Peri-implant soft tissue augmentation with a porcine collagen matrix. J Oral Res 2014;3:244-248. DOI: 10.17126/joralres.2014.055.

18. Adibrad M, Shahabuei M, Sahabi M. Significance of the width of keratinized mucosa on the health status of the supporting tissue around implants supporting overdentures. J Oral Implantol 2009;35(5):232-237. DOI: 10.1563/AAID-JOI-D-09-00035.1.

19. Bassetti RG, Stahli A, Bassetti MA, et al. Soft tissue augmentation around osseointegrated and uncovered dental implants: a 
systematic review. Clin Oral Investig 2016;21(1):53-70. DOI: 10.1007/ s00784-016-2007-9.

20. Frisch E, Ratka-Kruger P, Ziebolz D. A new technique for increasing keratinized tissue around dental implants: the partially epithelialized free connective tissue graft. retrospective analysis of a case series. J Oral Implantol 2015;41:467-472. DOI: 10.1563/AAID-JOI-D-13-00006.

21. Souza OMM, Neri JFA, Topazio L, et al. Influence of tissue biotype in the morphoesthetic functional behavior of the periimplant tissue: a literature review. Dental Press Implantol 2012;6(2):56-66.
22. Noelken R, Geier J, Kunkel M, et al. Influence of soft tissue grafting, orofacial implant position, and angulation on facial hard and soft tissue thickness at immediately inserted and provisionalized implants in the anterior maxilla. Clin Implant Dent Relat Res 2018;20:674-682. DOI: 10.1111/cid.12643.

23. Bassetti M, Kaufmann R, Salvi GE, et al. Soft tissue grafting to improve the attached mucosa at dental implants: a review of the literature and proposal of a decision tree. Quintessence Int 2015;46(6):499-510. DOI: 10.3290/j.qi.a33688. 